\title{
Progress in Surface Treatment and Processing of Coatings
}

\author{
SANDIP P. HARIMKAR ${ }^{1,2}$ \\ 1.-School of Mechanical and Aerospace Engineering, Oklahoma State University, Stillwater, \\ OK 78078, USA. 2.—e-mail: sandip.harimkar@okstate.edu
}

The surface treatments of materials and processing of coatings are becoming increasingly important for imparting functional properties, repairing the surfaces, and protecting the surfaces from conditions of stress, temperature, and corrosive media. The processing approaches involving surface cleaning and finishing, plating and electroplating, dip and conversion coatings, vacuum and controlled atmosphere coatings, surface modification using high-energy and particle beams (laser surface processing and ion implantation), and heat treatments (flame, induction, and high-energy beams) have all been successfully implemented to improve the surface properties and functionalities of materials. The advancements in the surface treatments and coatings processing have kept pace with the advances in the materials development. Novel processes have been regularly introduced and the existing processes have been continuously adapted for surface engineering of materials that are becoming increasingly important in new design considerations. The surface engineering of light alloys, ceramics, and amorphous/nanostructured materials is gaining unprecedented momentum. Metallurgical (interfacial bonding, elemental redistribution, and defects/porosity/cracking), manufacturing (noncontact, rapid, and flexible processing), environmental (eco-friendly and benign processing), and health (nontoxic materials and processing) considerations are becoming increasingly important in the surface treatments and processing of coatings.

The TMS Surface Engineering Committee regularly organizes symposia in TMS/Materials Science \& Technology (MS\&T) meetings and publishes feature topics in the TMS journal JOM to capture the advances the field. At the recently concluded TMS 2014 Annual Meeting (San Diego, CA; 16-20 March 2014), the committee organized a symposium titled Advances in Surface Engineering: Alloyed and Composite Coatings III. The symposium featured 49 presentations including nine invited talks in the

Sandip P. Harimkar is the guest editor for the Surface Engineering Committee of the TMS Materials Processing \& Manufacturing Division, and coordinator of the topic Surface Engineering of Materials in this issue. areas of processing (thermal spray, laser, and friction stir, and electrochemical processing) and properties (wear, oxidation/corrosion, mechanical, and high-temperature properties) of alloy and composite coatings. The Surface Engineering Committee also organized two joint sessions titled "Recent Developments in Biological, Electronic, and Functional Thin Films and Coatings" with the TMS Thin Films and Interfaces Committee. The joint sessions featured an additional 23 presentations including four invited talks on the topics coatings for biomedical applications, multilayer coatings, anticorrosive coatings, and thin films. The committee encourages the participation of industry in its programming. In addition to the presentations by university researchers and students, the symposium also featured several talks by researchers working in industry and government research laboratories. The committee recognizes the importance of partnership between the universities and industries in advancing the state-of-the-art in the areas of surface engineering. The committee is committed to organizing regular symposia and publishing feature issues to provide a platform for useful discussions on evolving topics in surface engineering. This issue of JOM presents five articles, including four articles based on presentations made at the TMS 2014 Annual Meeting on the topics of surface treatment and processing of coatings.

In the article titled "Aqueous Corrosion Behavior of Micro Arc Oxidation (MAO)-Coated Magnesium Alloys: A Critical Review," L. Rama Krishna and G. Sundararajan examine the prospects of the relatively novel and eco-friendly micro-arc oxidation (MAO) process in aqueous corrosion protection of $\mathrm{Mg}$ and its alloys. The authors present a critical review of the influence of MAO processing parameters such as electrolytic composition, presence of insoluble additives in the electrolytes, electrical parameters, and substrate composition on the corrosion resistance of $\mathrm{Mg}$ alloys. The authors conclude that the MAO process offers distinct advantages such as complete crystalline structure, good coating-substrate bonding, and the ability to tailor 
composition including formation of duplex coatings when compared to competing surface modification technologies for $\mathrm{Mg}$ alloys.

In the second contribution titled "Al-Si-Mn Alloy Coating on Aluminum Substrate Using Cold Metal Transfer (CMT) Welding Technique" the authors G.P. Rajeev, M. Kamaraj, and S.R. Bakshi examine the CMT process as a weld overlay technique for forming coatings. The effects of welding process parameters on attributes such as weld dilution and bead angle, and the hardness profile in depth are investigated in the article. The authors suggest that the CMT process can be used efficiently for the deposition of thick coatings and repair of welds for $\mathrm{Al}$ alloys.

The third paper titled "Tribology and Superhydrophobicity of Laser-Controlled-Melted Alumina Surfaces with Hard Particles" by B.S. Yilbas, B. Bhushan, B.J. Abdul Aleem, and Z. Gaseem investigates the mechanical properties (scratch resistance, friction coefficient, microhardness, and fracture toughness) and hydrophobicity (based on contact angle measurements) of laser-melted alumina composite surfaces. Thin carbon films consisting of uniformly distributed $\mathrm{WC}, \mathrm{SiC}$, and $\mathrm{B}_{4} \mathrm{C}$ were applied on the surfaces of alumina ceramic tiles prior to controlled laser surface melting. The authors report that the laser surface melting results in the development of a texture consisting of micropoles/nanopoles and microcavities, enhancing contact angle at the surface. It was observed that the hard particles get partially embedded in the remelted alumina ceramic surface and significantly improve the surface microhardness.

The fourth paper titled "Structural Relaxation and Nanocrystallization Induced Laser Surface Hardening of Fe-Based Bulk Amorphous Alloys," by A.K. Singh, S.H. Alavi, S.R. Paital, N.B. Dahotre, and S.P. Harimkar discusses microstructural modifications, thermal effects, and hardness improvements in sintered $\mathrm{Fe}_{48} \mathrm{Cr}_{15} \mathrm{Mo}_{14} \mathrm{Y}_{2} \mathrm{C}_{15} \mathrm{~B}_{6}$ amorphous alloys irradiated with a continuous wave Nd:YAG laser. The authors report about $13 \%$ and $30 \%$ increase in surface microhardness due to laser irradiation-induced structural relaxation and nanocrystallization, respectively. With high surface hardness (1360-1560 $\mathrm{HV}$ ) and hardening in submillimeter depths, the laser surface heating presents an interesting possibility of shallow hardening of amorphous alloys for tribological applications.

In the fifth paper titled "The Effect of Grain Size on the Cyclic Oxidation of NiCoCrAlY" by C. Kaplin, J. Fassoni, and M. Brochu, the authors present systematic investigations on the cyclic oxidation behavior of $\mathrm{NiCoCrAlY}$ samples sintered with and without prior cryomilling. It is reported that, after thermal cycling at $1000^{\circ} \mathrm{C}$ up to 200 cycles, the fine-grained samples (cryomilled and sintered) exhibited lower mass gain when compared to samples sintered without cryomilling. The authors attribute the observed difference in oxidation behavior to an accelerated $\theta \rightarrow \alpha$ transition and enhanced scale adherence in the cryomilled and sintered samples.

On behalf of the organizers of the TMS 2014 surface engineering symposium, I thank all the invited, contributed, and student speakers, and the participants for making the symposium a success. I also thank the authors for contributing their research papers, the reviewers for timely review of the manuscripts, and the TMS staff for providing editorial support in preparing this JOM feature issue. I hope that the readers find the evolving topics of surface treatment and coatings processing captured in this issue interesting. The Surface Engineering Committee welcomes the ideas and suggestions for further improving the programming and publishing activities of the committee.

\section{ACKNOWLEDGEMENT}

I would like to thank Drs. Arvind Agarwal, Roger Narayan, and Jeff DeHosson for their suggestions and support. I would also like to acknowledge the funding from the National Science Foundation (Grants CMMI 0969255 and CMMI 1149079) for supporting my travel to TMS conferences and our research activities in the areas of laser surface engineering of materials. 